La Tribuna. Cadernos de Estudos da Casa-Museo Emilia Pardo Bazán

Núm. 9, $215-238$

(C) 2012-2013. Casa-Museo Emilia Pardo Bazán

\title{
Emilia Pardo Bazán en el Santuario de Pastoriza: dos cartas inéditas y una benévola censura
}

\author{
Juan Félix Neira Pérez \\ (IES FERNANDO BLANCO DE CEE - A CORUÑA) \\ jfelix@edu.xunta.es
}

(recibido outubro/2013, revisado decembro/2013)

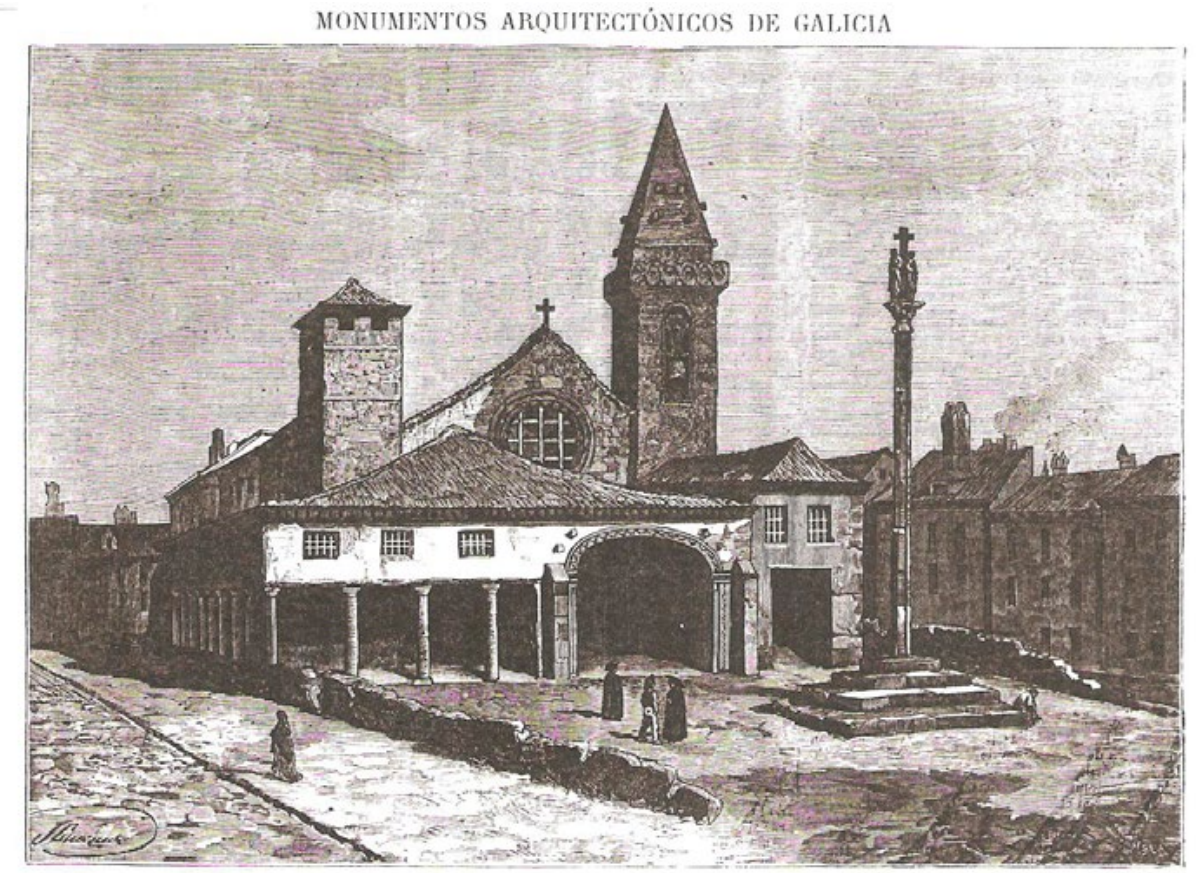

IGLESIA DE SANTA MARIA DEL CAMBO, COLEGIATA DE LA CORUÑ̀.

RESUMEN: Emilia Pardo Bazán acude en junio de 1887 al santuario de Pastoriza de Arteixo, cerca de A Coruña, para ofrecer a la Virgen la corona de laurel y encina regalada pocos días antes, al regresar de Madrid, por el Círculo Mercantil de esa ciudad. Allí concibe la idea de escribir una obra acerca de la leyenda de la Virgen de Pastoriza, una especie de guía que además serviría para promocionar el santuario. El cura párroco propone que sea el santuario el que la publique. 
Las dos cartas inéditas aquí exhumadas, depositadas en el Archivo Histórico Diocesano de Santiago de Compostela, están relacionadas con el dictamen de censura preceptivo -también inédito- encargado por el Arzobispado para permitir la publicación de la obra. Pese a algunos reproches, como un adjetivo usado con poco rigor teológico o algún pasaje impregnado de cierto 'naturalismo filosófico', La Leyenda de la Pastoriza, opúsculo hoy absolutamente olvidado en los estudios de Pardo Bazán, obtiene el nihil obstat y el imprimatur del censor, y se publica dos meses después.

PALABRAS CLAVE: Pardo Bazán, santuario de Pastoriza, leyenda, censura, naturalismo filosófico.

ABSTRACT: In June, 1887, Emilia Pardo Bazán went to Pastoriza sanctuary in Arteixo, near Coruña. She wanted to offer the Virgin the wreath made of holm oak and bay leaves which had been a present given to her by the Mercantile Society of Coruña, only a few days before, when she left Madrid. It was in Pastoriza sanctuary where she conceived the idea of writing a work about the Virgin of Pastoriza's legend a kind of guide which would also help to promote the sanctuary.

The parish priest suggested that it should be published by the sanctuary. The two unpublished letters here exhumed, placed in the Diocesan Historical Archive, are related to the perceptive censorship report -also unpublished- which the Archbishopric asked for in order to allow the work to be published. Despite some reproach -an adjective being used with little theological rigor or some passage filled with a certain philosophical naturalismThe Legend of Pastoriza, a work which in utterly forgotten today in the studies on Pardo Bazán, achieved the nihil obstat as well as the censor's imprimatur and it was published two months later.

KEY WORDS: Pardo Bazán, Pastoriza sanctuary, legend, censorship, philosophical naturalism.

Mariae Theresiae, uxori carissimae

(dedicatoria)

La fe no se destruye con razones: es error imaginar que hay argucia que eche abajo un sentimiento.

La fe es como el amor. (La madre Naturaleza, VIII).

\section{CINCEL Y PLUMA EN LOOR DE LA VIRGEN}

La temporada estival de 1887 la inicia en su tierra natal doña Emilia Pardo Bazán con la honrosa deferencia del Círculo Mercantil de A Coruña, que condecora a la escritora con una corona de laurel y encina, tras regresar de Madrid. Su llegada a Galicia tampoco pasa desapercibida a su amigo el "bardo" Eduardo Pondal, que la celebra con el poema "Do aleiro nativo", escrito y publicado también en 1887 (Ferreiro 1991: 104). Ella le corresponde, ese mismo año, difundiendo a Pondal en Portugal y Francia con la publicación del artículo "Les poètes galiciens. Le barde Eduard Pondal" en Les Matinées Espagnoles (Freire López 1991: carta 1, n. 7).

Ocho días después del homenaje del Círculo Mercantil doña Emilia deposita la corona vegetal en el arteixán Santuario de Pastoriza, adonde acude acompañada 
de otros amigos. Ella misma nos lo cuenta en el capítulo II, titulado "Cómo se me ocurrió escribir esta leyenda", de La Leyenda de la Pastoriza ${ }^{1}$, escrita en este mismo verano de 1887:

El domingo 12 de Junio de 1887 subí al Santuario de Pastoriza, con objeto de oir una misa en el altar de la Virgen, depositando en él la corona de laurel y encina que me había ofrecido el Círculo Mercantil de la Coruña, ocho días antes, á mi regreso de Madrid (Pardo Bazán 1887: 11).

Aunque los días de mayor concurrencia eran en octubre, durante todo el año muchos romeros convirtieron este lugar en foco de peregrinación y devoción; de A Coruña, de la que dista el Santuario unos cinco kilómetros, acudían muchos fieles (Cebrián 1982: 85). Doña Emilia no pasa por alto este hecho:

Muy grande es la devoción á este antiquísimo Santuario, y fuerza es decirlo, el hielo de la indiferencia contemporánea no ha enfriado un punto la atmósfera de la Pastoriza. La gente artesana y humilde de la Coruña le profesa cariño especial; y sobre todo, las operarias de la Fábrica de tabacos se pierden por su Virgen muy amada (Pardo Bazán 1887: 67).

La desatención de que ha sido objeto La leyenda de la Pastoriza nos ha privado de descifrar todavía más la topografía literaria de Marineda, ya que "La Coruña se convierte en una entidad literaria, en una comunidad bautizada con el eufónico nombre de Marineda". Añadimos descifrar porque "sus barrios, sus plazas, sus calles, sus alrededores, son rebautizados también" (Varela Jácome 1995: 41). En efecto, el Santuario de Pastoriza es un alrededor, por supuesto rebautizado.

Una de las cigarreras coruñesas de la novela obrera La Tribuna (1882) se Ilama Guardiana, porque "era nacida al pie del santuario de Nuestra Señora de la Guardia, tan caro a Marineda, y según ella misma decía, la Virgen le había de dar la gloria en el otro mundo, porque en éste no le mandaba más que penitas y trabajos". Al relatar la mísera existencia de la cigarrera, apunta la autora que "Guardiana mendigó, esperó a los devotos que iban al santuario, rondó a los que llevaban merienda, pidiéndoles las sobras, y tanto hizo, que nunca les faltó a sus chiquillos de comer,

\footnotetext{
1 Editada en A Coruña por José Miguez Peinó y Hermano Impresores en 1887, la Tipografía "El Ideal Gallego" la reimprimió en 1939. Hoy es fácilmente accesible gracias a la copia digital en http://www. galiciana.bibliotecadegalicia.xunta.es, que ha sido la manejada para este trabajo. Esta obra ha pasado prácticamente inadvertida en la bibliografía pardobazaniana. Las biógrafas Bravo-Villasante (1973) y Pilar Faus (2003) no la mencionan siquiera. Sí alude a ella Paredes Núñez (1984: 19, 21-22), a propósito de obras que trataron la "actividad folklórica en Galicia", y a la que califica como "folleto propagandístico"; y también la menciona de pasada Varela Jácome (1995: 14). Al margen de los estudios literarios, Cebrián Franco señala que las "bellas leyendas" ligadas al Santuario "han merecido la atención de la pluma de la Condesa de Pardo Bazán, que le dedicó una de sus obras” (1982: 86).
} 
aunque ella ayunase a pan y agua" (Pardo Bazán 1995: 115). No cabe duda de que la alusión remite a un espacio del extrarradio de Marineda, por la contraposición explícita en algunas líneas más adelante: "Del casco mismo de Marineda procedía la otra amiga de Amparo", apodada Comadreja, se lee en este mismo capítulo XI, titulado "Pitillos" (Pardo Bazán 1995: 116). Pero no acaban aquí los indicios que apuntan a la identificación que proponemos; en el capítulo XXIV, por título "EI conflicto religioso", la contraposición no se plantea ahora en términos de personajes y de barrios, sino de devociones:

Jamás produjo tanto la colecta para la procesión del Santo Entierro y novena de los Dolores; y, por último, sin ocasión alguna tuvo el numen protector de la fábrica, la Virgen del Amparo, tantas ofertas, culto y limosnas, sin que por eso quedase olvidada su rival Nuestra Señora de la Guardia, estrella de los mares, patrona de los navegantes por la bravía costa. (Pardo Bazán 1995: 181).

Cabe recordar aquí el patrocinio de la Virgen de Pastoriza a las gentes del mar, como señala doña Emilia en su Leyenda. Acertó doña Emilia con el nombre ficticio de Nuestra Señora de la Guardia, si tenemos en cuenta el carácter de atalaya del enclave sagrado, desde el que se vislumbra un dilatadísimo horizonte así de las tierras coruñesas como del Atlántico, cual faro gemelo de la Torre de Hércules:

...y al Sur se alza el faro moral encendido por la fe cristiana, el que interviene y protege y salva y guía al puerto cuando ya el marino se cree perdido sin remisión; el numen invocado en la última extremidad, la Virgen marinera, la Estrella de los mares. (Pardo Bazán 1887: 9).

Por último, parece oportuno señalar qué escribe Carré Aldao a propósito de las advocaciones marianas en A Coruña. De la Virgen de la Colegiata y parroquial de Santa María del Campo dice que es

objeto constante de veneración para la gente marinera, a la que Ilaman Estrella del Mar, aún hoy desde sus embarcaciones, al acercarse al puerto coruñés, envían su oración a las tres Marías, o sea a la de la Colegiata, la de Oza y la de Pastoriza, todas dentro del antiguo coto de la ciudad. (Carré Aldao 1928: 525).

Sin embargo, la autora no recrea en la novela la romería de Arteixo en el capítulo XXV, titulado "Primera hazaña de la Tribuna", sino la del "alto de Aguasanta", donde se invoca a Santa Margarita "para que nos libre de «males extraños»" (Pardo Bazán 1995: 185-186).

\footnotetext{
2 Alusión a la romería de Santa Margarita, a finales de agosto, celebrada en el cerro o "alto" homónimo, entonces en las afueras de la ciudad. La fuente milagrosa o "Aguasanta" es elemento frecuente en el culto a Santa Margarita (Carré Aldao 1928: 642-643 y 659-660). Doña Emilia "recuerda lo mucho que disfrutaba bebiendo agua fresquísima en el cerro de Santa Margarita” (Faus 2003: 44).
} 
Conviene, antes de proseguir, ubicar en su contexto La Leyenda de Pastoriza. La exhaustiva biografía de Pilar Faus (2003: 373 y ss.) nos permite reconstruir el verano de 1887 con bastante precisión. No será la única la excursión a Arteixo, pues sabemos que a principios de septiembre doña Emilia está en Ourense, invitada al homenaje tributado al Padre Feijoo, a quien dedicó un discurso. El día 22 se halla en Mondariz ${ }^{3}$, al menos hasta el 1 de octubre. Después visita lugares emblemáticos de la provincia ourensá como Celanova o San Estebo de Ribas do Sil, vivencias que recogerá en De mi tierra (1888). A 11 de noviembre se encuentra ya en Madrid. Y en invierno, su querida Francia, París. Faus (2003: 373 y ss.) considera rápida y exitosa la carrera de la Pardo Bazán en esta década de los ochenta, con su cenit en el 1887, año en que publica la Leyenda. En el mismo sentido se pronuncia Varela Jácome (1995: 14), que ve en este decenio "la primera etapa realmente efectiva de la producción pardobazaniana", a la que pertenecen ocho novelas y otras obras de diversa naturaleza, entre las cuales cita San Francisco de Asís (1882) -al que nos referiremos después-, Folklore gallego -cuyo espíritu conecta con la obra que aquí analizamos-, La Leyenda de Pastoriza (1887), Mi romería o la citada De mi tierra (ambas de 1888).

Retomemos la visita al Santuario, cuyo rector, Don Víctor Cortiella y Somoza, recibe a los excursionistas. Tras alabar las excelencias del lugar, uno de ellos concibe la idea de señorear el paraje con la pétrea presencia de la Madre de Dios:

Uno de los expedicionarios, mi amigo de la niñez Alvaro Torres, en quien se unen las prendas de artista, rico y generoso, discurrió que el complemento de tan romántico sitio y tan extenso y grandioso panorama, sería una estatua de la Virgen labrada en piedra, imitando en lo posible el candor y la rigidez de las efigies bizantinas. (Pardo Bazán 1887: 17).

Complemento magnífico del cincel sería sin duda la pluma, debió de pensar doña Emilia, que quizá por modestia, o simplemente por hacer honor a la verdad, no reconoce explícitamente que fue ella la que sugirió la idea de inmortalizar negro sobre blanco la historia del Santuario. El párroco recoge el guante: la publicación correrá de su cuenta:

...de tal modo se cruzaban indicaciones, preguntas y respuestas, que no puedo recordar con exactitud si fui yo misma ó alguno de los circunstantes quien habló primero de la Leyenda que convenía escribir, en lenguaje Ilano y sencillo, para que los peregrinos y devotos del Santuario conociesen y conservasen en la memoria aquellas tradiciones, recuerdos y particularidades que tanto nos interesaban á nosotros. Al punto el cura se ofreció a publicarla y discurrió que se vendiese á

\footnotetext{
3 Yolanda Pérez Sánchez (2004: 271) señala que es la primera vez que acude a tomar las aguas como atención a sus dolencias hepáticas, según refleja el “Álbum de Honor” del afamado balneario.
} 
beneficio del Santuario; pareció acertadísimo el proyecto, y sin más, antes de salir del hueco del peñasco, me encontré investida con el título de cronista de la Virgen montañesa -la Virgen de los reyes suevos. (Pardo Bazán 1887: 18- 19).

Dicho y hecho. Todavía hoy podemos, dos siglos después, contemplar la estatua de la Virgen comenzada a concebir en esta jornada dominical del 12 de junio de 1887, pero sin duda en un entorno muy diferente ya, de una degradación medioambiental y un feísmo dispares con respecto al locus amoenus que doña Emilia y sus acompañantes nos sugieren. $Y$ del cumplimiento de la palabra dada por la escritora da fe la edición misma de la obra: "Esta Leyenda es propiedad del Santuario de Nuestra Señora de Pastoriza, por donación de la autora. Queda hecho el depósito que marca la ley" (Pardo Bazán 1887: s.n.).

Nos ocuparemos, en primer lugar, de la erección de la escultura, a la que no fueron ajenos ni doña Emilia ni sus padres. Dejaremos para el final todo lo relativo a la "ofrenda" literaria, asunto nuclear de este nuestro trabajo.

\section{EL VOTO ESCULTÓRICO: "OBRA DEL HUMILDE CANTERO DE PUENTEAREAS"}

El amigo de la Pardo Bazán no había prometido la estatua a humo de pajas. En el capítulo X, titulado "La Virgen de granito", la escritora alaba además el acierto del oferente:

Alvaro de Torres Taboada, donatario de la estatua que en breve descollará sobre el dolmen y castro de Pastoriza, ha tenido el buen gusto de no encargársela á un escultor de oficio, sinó sencillamente á un cantero. (Pardo Bazán 1887: 61).

Tal cantero era José Couto, natural de Ponteareas, con el que doña Emilia tuvo ocasión de hablar. Ella no desperdicia la posibilidad de dejar por escrito, cual crítica de arte, sus impresiones sobre el resultado final:

Couto me ha asegurado que sabe dibujo; yo abrigo vehementes sospechas de que no hay tal; lo que sucede es que este oscuro é inspirado artífice no se da cuenta de que el mayor mérito de su trabajo consiste precisamente en su carácter algo primitivo é instintivo, en sus imperfecciones de diseño; y que si él fuese un escultor con todas las reglas, su estatua probablemente resultaría, no sólo inadecuada al objeto, sinó vulgar e insufrible, adoleciendo de ese modernismo de las esculturas francesas, que enfría el corazón (Pardo Bazán 1887: 62).

Tras realizar una descripción de la talla, concluye la Pardo Bazán que, "Colocada en su sitio la estatua, poseerá la Coruña un monumento original y poético; y á más de 
un turista ${ }^{4}$ ha de sorprender y cautivar la obra del humilde cantero de Puenteareas". (Pardo Bazán 1887: 63).

La vinculación de doña Emilia al Santuario no se reduce sólo a la escritura de la Leyenda, sino también al acto de la erección de la talla pétrea, en el que también participan sus padres. Así lo atestigua el acta de colocación de la imagen, conservada en el fondo documental parroquial:

En el nombre de Dios Omnipotente y de la $S^{\text {ta }}$. Virgen Maria de Pastoriza, Madre inmaculada del Verbo eterno. Para perpetua memoria. (...) descubrióse a la pública veneración teniendo por dosél el firmamento y por templo agrias montañas la "Virgen de granito" que erigió sobre el peñon de la "cuna" que por tantos siglos prestó albergue a la Pastoriza de Rechiario, la piedad de Alvaro Torres Taboada y el ingenio del humilde picapedrero José Couto de Puenteareas, y que inmortalizará con "La Leyenda" Emilia Pardo Bazán. (AHDS, F. Parroquial de N. S. de Pastoriza, 1887, sección $1^{\text {a }}$, legajo A, núm. 15).

Firman este documento el donante Álvaro Torres Taboada y el párroco Víctor Cortiella, y destacadas personalidades como José Sánchez Bregua, Capitán General de Galicia. Junto a la firma de Emilia Pardo Bazán, estampan la suya sus padres: "La Condesa de Pardo Bazán" y "El Conde de Pardo Bazán". También José Couto, "el escultor de la estatua", propiamente cantero según doña Emilia, amén de otras personas como médicos, curas, alcaldes, periodistas, diputados provinciales, etc.

\section{EL VOTO LITERARIO: "HAY QUE RESPETAR Y PATROCINAR LA LEYENDA"}

De la curiosidad intelectual y consiguiente hiperactividad de doña Emilia ("con férvidas ansias" regresa a su tierra, dice su amigo Pondal en el poema a ella dedicado este mismo año), que tiene entonces 35 años, no cabe aportar ya gran cosa sin caer en las lindes de Perogrullo. Apenas concebido el proyecto, la escritora innata que doña Emilia lleva dentro ya no descansa:

Bajamos del monte aun más alegres que sofocados, que no es poco decir; y como al llegar al atrio faltaba todavía media hora larga para la misa de doce, empecé a llenar los deberes del cargo que se me había conferido, rogando al cura que me diese todas las explicaciones posibles acerca de la antigua inscripción en piedra tosca, empotrada en el muro del lado Norte de la actual iglesia (Pardo Bazán 1887: 19).

\footnotetext{
4 Es de la autora la cursiva, justificada por el carácter de neologismo del término inglés tourist, procedente del francés tour ("vuelta, giro"), vocablo que se afianzó, desdela década de 1830, para designar un nuevo modelo de viajero. Tras un eclipse en el uso del término, vuelve a emplearse a fines de siglo (García Morales 2011: 162; Fernández Fuster 1974: 21).
} 
Lo mismo cabe decir del afán con que acomete la empresa, en la que se vuelca con toda responsabilidad, para lo cual impetra cualquier tipo de información:

Sea como quiera, por estar bastante frescos estos sucesos, puede ser que no falte en la Coruña quién tenga de ellos más minuciosos pormenores; y si es así, le agradeceré que me los comunique, para que las nuevas ediciones de este librito salgan enriquecidas con datos más exactos (Pardo Bazán 1887: 53).

Es este espíritu de laboriosa responsabilidad, de anhelo por la obra bien ejecutada por debidamente documentada, lo que nos sitúa en la primera de las dos cartas inéditas ${ }^{5}$ que aquí exhumamos, remitida al párroco don Víctor Cortiella:

\section{Sr. Cura Parroco de Pastoriza}

Granja de Meirás- 29 de Junio de 87

Distinguido señor y amigo: como el tiempo pasa y $\mathrm{V}$. deseará defijo poder ver impresa en setiembre la Leyenda de Pastoriza, le ruego se sirva comunicarme cuantos datos le sea posible, á fin de hacer más nutrida la obrita ó folleto. Ahora tengo algunas horas y puedo despacharlo.

Sabe que es su muy verdadera amiga y muy agradecida á todas sus amables atenciones y cariñosa hospitalidad

Emilia Pardo Bazán

P.D. Las cartas y recados para mí se reciben en la casa del lado de la mia (y de V) calle de Tabernas, donde vive la Viuda de Domínguez el municipal. (AHDS, F. Parroquial de N. S. de Pastoriza, 1887, sección 1a, legajo A, núm. 15).

Habían transcurrido diecisiete días desde la excursión al Santuario. La designación de la Leyenda como "obrita o folleto", así como la pretensión de "despacharla" en "algunas horas", parecen revelar la consideración de tarea menor por parte de la escritora que, en referencia a la publicación de obras de poca entidad en el prólogo a De mi tierra, datado el 15 de febrero de 1888, afirma: "...aborrezco los folletitos semejantes á obleas, que no hay forma de encuadernar y en todas las bibliotecas estorban". (Pardo Bazán 1984: 8).

Aproximadamente mes y medio más tarde, doña Emilia pide a Cortiella -es la segunda carta inédita- que agilice las gestiones ante el Arzobispo de Santiago, a la sazón don Victoriano Guisasola Rodríguez (1886-1888), para que la "obrita o folleto" pase a imprenta y vea la luz:

\footnotetext{
5 Thion Soriano-Mollá (2005) cuantifica en 427 las cartas publicadas de doña Emilia, número escaso si tenemos en cuenta su intensa y dilatada vida social y literaria. Los autógrafos que aquí exhumamos (vide anexo fotográfico), perfectamente legibles, están escritos sobre papel de color marfil, de 12 x $18 \mathrm{~cm}$ y 16 '5 × 21'5 cm respectivamente. Hemos reproducido con escrupuloso respeto todas las características de la escritura (ortografía, abreviaturas, subrayados, etc.) de los documentos de archivo reproducidos en este artículo.
} 
Hoy 18 de Agosto de 1887

Sr. Dn. Victor Cortiella

Mi más distinguido amigo: adjunta la que dirijo al Sr. Arzobispo: V. me hará el favor de agregar á ella lo que considere oportuno, y de enviarla cuanto antes por el correo. Si tiene V. algun amigo en Santiago, no estará demás que le encargase el pronto despacho de este negocio.

Su verdadera amiga

q. bs m.

Emilia Pardo Bazán (AHDS, F. Parroquial de N. S. de Pastoriza, 1887, sección $1^{\text {a }}$, legajo A, núm. 15).

Desconocemos hasta qué punto se conocían de antes párroco y escritora; de las cartas se deduce cierta familiaridad que bien pudiera ser simple cortesía. Sí debemos inferir que el rector no carecía de inquietudes intelectuales, amén de pastorales quizá también crematísticas dado el empuje propagandístico que supondría la "obrita o folleto"-, ya que la escritora le pide información y además nos lo presenta como un párroco ilustrado:

Poco tardamos en hallar al párroco don Víctor Cortiella, quien mostró desde las primeras palabras ser persona extraordinariamente afable y culta, además de viva, despierta, enterada de los menores ápices de su encargo y diligentísima en cumplirlo. (Pardo Bazán 1887: 15).

Ello se manifiesta en el interior del Santuario, que "revela en cada detalle la actividad y excelente gestión del señor Cortiella" (Pardo Bazán 1887: 65). De las inquietudes culturales de éste también da fe una carta ${ }^{6}$ en que solicita al académico Eduardo Saavedra la lectura de la inscripción medieval del muro norte de la iglesia, a la que también se refiere la escritora en la Leyenda.

El acta de colocación de la estatua nos informa de los méritos del doctor Cortiella, cura rector propio del santuario y parroquia de Santa María de Pastoriza y sus filiales San Tirso de Oseiro (parroquia natal de Manuel Murguía, con quien tanto y tan agriamente polemizó la Pardo Bazán) y San Martín de Suevos. Ostentaba también los títulos de Capellán de Honor de Su Majestad el Rey, Caballero de la Real y Distinguida Orden Española de Carlos III y Comendador de la Americana de Isabel la Católica. Sabemos también que desde 1893 ya no ejerce la cura de almas en Pastoriza, sino en la parroquia de San Jorge de A Coruña ${ }^{7}$, muy cerca por tanto del

\footnotetext{
6 AHDS, Fondo Parroquial de Nuestra Señora de Pastoriza, Sección 1ª Legajo A, núm. 20.

7 Don Víctor siguió manifestando su natural sensibilidad por el arte en su nuevo destino: "Uno de sus últimos rectores [de la parroquia de San Jorge], el señor don Víctor Cortiella, mejoró grandemente el interior, concluyó la torre y adornó con estatuas de granito, de mediana traza, las hornacinas de la fachada, que ocuparan anteriormente otras estatuas y que dice la tradición fueron derribadas y hechas pedazos por una explosión de pólvora inmediata al templo”. (Carré Aldao 1928: 541).
} 
domicilio de doña Emilia en la calle Tabernas. Fue asimismo Arcipreste de Faro, y por tanto de las parroquias de la ciudad de A Coruña. Nacido en Betanzos, murió como rector de San Jorge, en 1911, a los setenta y dos años de edad.

Dos breves apuntes biográficos restan respecto a las misivas. Doña Emilia pasa el verano de 1887 en Meirás, que entonces llaman Granja, ya que los términos Torres y Pazo son posteriores, comprensibles a la luz de reformas que exigieron abultada inversión en una "ambigua y un tanto presuntuosa arquitectura" (Grupo de investigación La Tribuna 2009: 39, n. 3). De hecho se han relacionado estas reformas con las relaciones aristocráticas de su propietaria, "motivo de la construcción de las Torres de Meirás, su refugio durante parte del año, edificio levantado para impresionar y dejar constancia del peso de su sangre aristocrática" (op. cit.: 62).

Dice en la Leyenda, con respecto a las panorámicas que se divisan desde la Cuna de la Virgen:

Si no me engañan los ojos, por allá se divisa el comienzo de la ría de Sada; y, entre las dos rías, asoma una mancha oscura, que es el conocidísimo y familiar paisaje de San Pedro de Nos, Iñás y Oleiros, y aun un trozo de Meirás, donde tiene su asiento la rústica Granja ${ }^{8}$ (Pardo Bazán 1887: 33).

El padrón municipal de A Coruña de 1886 registra censados, en la casa familiar número 11 de la Calle Tabernas -citada en la carta-, a los padres de doña Emilia, a ella y a sus hijos, pero ya no a José Quiroga, por la probable ruptura de la convivencia conyugal (Barreiro Fernández 2008: 98).

Desde 1886, en cierto modo annus horribilis, sólo pasará los veranos en Galicia, reservando los inviernos para el mundano y cortesano Madrid. Si creemos a BravoVillasante (1973: 94-95), desde la discreta y amigable separación de su marido José Quiroga, doña Emilia suprime, al firmar, la J inicial de José que escribía ante su nombre de pila, deferencia hacia el pusilánime e incomprensivo esposo, conforme al uso aristocrático. Ahora será siempre Emilia o Emilia Pardo Bazán, como apreciamos ya en estas cartas. Ella sola, con su reivindicación de independencia vital y literaria, sin su marido, cuya cortedad de miras le impidió apoyarla en sus inquietudes literarias.

\section{EL DICTAMEN DE CENSURA: "FÉ CATÓLICA Y SANA MORAL"}

El asunto acerca del cual iba a escribir la Pardo Bazán, así como el apoyo decidido del párroco a la Leyenda exigían un informe previo en que la autoridad eclesiástica autorizase la publicación de la "obrita o folleto", que sabemos ya finalizada a 20 de agosto, gracias al documento que sigue:

\footnotetext{
${ }^{8}$ Cursiva en el original.
} 
Por el presente damos comision al Sr. Lic. D. Manuel Ojea, Canónigo Magistral de la Real Colegiata de Sta Maria del Campo de La Coruña?, para que, examinando el original del librito intitulado La Leyenda de la Pastoriza, que trata de imprimir su autora $D^{a}$. Emilia Pardo Bazan, se sirva informarnos si contiene alguna cosa contraria á la fé católica y sana moral, por la que no pudieramos ni debieramos autorizar su publicación, como se nos pide.

Santiago 20 de Agosto de 1887. (AHDS, F. General, Instrucción Pública, 1777-1898, Censura para la impresión de trabajos, "Libros prohibidos. Otros antecedentes", núm. 473).

Conservamos el informe elevado al Arzobispo de Santiago, solo once días más tarde, por el licenciado don Manuel María Ojea, cuyo perfil profesional trazaremos más adelante. Conviene reproducir íntegra aquí la valoración que le mereció la obra de doña Emilia:

\section{Coruña Agosto 31 de 1887 Exmo. é Illmo. Señor Arzobispo de Santiago}

Mi respetadisimo Señor y Prelado: Adjunta remito á V. E. Illma. la contestacion al oficio de V. E. de fecha 20 de Agosto del corriente año, el que hé recibido con ocho dias de retraso debido á que el impresor nó terminó hasta el 28 del dicho mes la impresión de la Leyenda de la Pastoriza obra de la Sra. Da . Emilia Pardo Bazan.

Hé leido, Excmo. Sr., con todo detenimto y escrupulosidad la mencionada Leyenda y hé fijado de un modo especial mi atención en el parrafo, que en su principal pte. transcribo aquí, haciendo sobre él las observaciones, que abajo consigno y qe. someto al elevado criterio de V. E. Illma. Dice asi el parrafo, á que me refiero: "Cuando un sentimto. se impone lo mismo al refinado habitante de las grandes capitales que al humilde pescador de la brava y solitaria costa, es que ese sentimto está fundado en necesidades y exigencias generales del corazón humano, fuertes, poderosas, dignas de respeto. El Santuario, el camarin, el altar que guarda la imagen milagrosa, encierra tambien la esperanza y el consuelo de miles de almas, el rayo de luz que las alumbra $\mathrm{p}^{\mathrm{a}}$. que no estén del todo oscurecidas y tristes en este valle."

Esto dice la Sra. $\mathrm{D}^{\mathrm{a}}$. Emilia Pardo Bazan después de haber probado que el culto mariano no há decaido y resiste á la indiferencia y al racionalismo del siglo actual, prueba que funda en la inmensa concurrencia que acude á los Santuarios á dar culto á la Madre de Dios.

En otro parrafo despues de haber hablado del particularismo religioso con qe. muchos fieles distinguen y dan preferencia á alguna imagen de la Virgen sobre otras imagenes de la excelsa Madre de Dios, (si bien añade "claro está que la Madre de Dios es la misma en todas partes, y donde quiera que la invoquemos há de oirnos") dice: "La Iglesia catolica que reconoce y respeta los sentimtos naturales, siempre dio vado á estas preferencias y cariños, porque asi los sentidos auxilian á la fé y

\footnotetext{
9 "El personal asignado por el Concordato de 1851, y por el que fue la única Colegiata que quedó en Galicia por estar 'sita en capital de provincia donde no existe Silla Episcopal' (art. 21), es el de un abad presidente, que tiene aneja la cura de almas como parroquia y la jurisdicción directiva y económica de iglesia y cabildo; dos canónigos de oficio con los títulos de magistral y doctoral; ocho canónigos de gracia; seis beneficiados, dos de ellos de oficio y cuatro de gracia”. (Carré Aldao 1928: 531).
} 
el corazon descansa en lo que ama y conoce". Encuentro, Excmo. Sr., en estos dos parrafos algun tufillo, permitame V. E. la expresion, de naturalismo filosofico, porque me parece que en ellos se prescinde bastante del orden sobrenatural, de la verdad revelada. ¿Reclama el corazon humano por si mismo la satisfacción de esas necesidades espirituales, fuertes, poderosas, dignas de respeto, de que habla la Señora de Pardo Bazan en el $1^{\text {er }}$. parrafo trascrito? Es evidente que no. Sin la fé y las demas gracias sobrenaturales nada puede exigir el corazon humano ni hacer otra cosa alguna que al orden sobrenatural pertenezca. Solamte. ilustrados por la fé el corazon y los sentidos y ayudados con la divina gracia es como pueden ser auxiliares de la fé catolica, mantenerla firme y viva en nuestras almas, y no asi á secas como lo espresa la Sra. $\mathrm{D}^{\mathrm{a}}$. Emilia Pardo Bazan en el $2^{\circ}$ parrafo que transcribi. Es cierto que en la misma prueba que aduce de la estabilidad del culto mariano, presentandolo como un baluarte contra la indiferencia y racionalismo del Siglo XIX, da por supuesta la fé como causa engendradora de la devocion á Maria en los Santuarios que están dedicados de un modo especial á la Madre de Dios. Pero los citados parrafos en si mismos están muy poco barnizados con el tinte del orden sobrenatural y por eso hé dicho, Excmo. Sr. qe. tenian cierto tufillo de naturalismo filosofico. Y como á la vez en todo lo que espresa dha. Señora no hay proposicion alguna concreta en el sentido objetivo del escrito qe. se oponga al Dogma catolico, por eso, Excmo. Señor, consigné en la contestación al oficio de V. E. qe. la Leyenda de la Pastoriza obra de $\mathrm{D}^{\mathrm{a}}$. Emilia Pardo Bazan nada contenia contrario á la fé y á la moral, sometiendo, no obstante, mi pobre juicio al muy superior de V. E., por cuya razon hé transcrito literalmente los parrafos mas culminantes de la espresada Leyenda y seguiré transcribiendo algunos mas, que, si bien merecen atencion, no son de tanta importancia.

En otro lugar hablando del Pilar de Zaragoza, del cubo de la Almudena, de la cripta de la Soterraña de Avila añade "comprendemos que las imágenes de la Virgen no son para nosotros objeto de devocion tan solamte., sino que hacen el oficio qe. $p^{a}$. Francia la columna fundida con el bronce de los cañones ganados en cien batallas".

Me parece, Excmo. Sr., la comparacion algo profana y poco respetuosa á la Madre de Dios, si bien en el fondo los estremos de la comparación tienen algunos puntos de contacto. Dice en otra parte de la Leyenda la Señora Doña Emilia, despues de haber manifestado el cariño especial á la Virgen de Pastoriza, en cuyo altar "habia depositado la corona de laurel y encina que le habia ofrecido el Circulo Mercantil de la Coruña, ocho dias antes á su regreso de Madrid" por el triunfo literario obtenido en el Ateneo de dha. Capital del Reyno, "No necesitan justificarse estas especiales adhesiones que nos inspira una imagen con preferencia á todas las demas, pues son afecto bien natural hermano del que sentimos por la patria, por la tierra, por el pueblo nativo, por la casa nativa y hasta por los muebles viejos". Me parece, Excmo. Sr., que este afecto que profesamos á las imágenes sagradas debe ser muy superior, si es que está como debe estar, inspirado en la fé, al que profesamos á la patria, á la tierra y á la casa paterna, que, al fin, no es mas que un simple afecto natural.

Haciendo, en otro sitio, la descricion de la gruta en donde apareció la imagen de la Virgen dice, entre otras cosas, "ni tenia (la estatua de la Virgen) mas pabellon y dosel que la boveda soberana de lapiz lazuli que veiamos dilatarse con majestad infinita". Palabra esta ultima, que no me parece, en rigor teologico, adecuada á la descriccion de que se trata.

Lo restante de la Leyenda, Excmo. Sr., no es mas que pura historia del Santuario de Pastoriza, adornada con rasgos de erudición y entrelazada con hermosas flores 
poeticas. Hé hecho, Excmo. Sr., todo lo posible por desempeñar bien el cometido de V. E. Illma.

Mucho desea qe. hayan probado bien á V. E. I. las aguas de Caldas este su mas sumiso subdito y Capellan Q. B. el A. pastoral de V. E. Rvma.

Manuel Mª Ojea. (AHDS, F. General, Instrucción Pública, 1777-1898, Censura para la impresión de trabajos, "Libros prohibidos. Otros antecedentes", núm. 473).

Se centra el canónigo en cinco pasajes, que cita entrecomillados. Todos pertenecen a los dos primeros capítulos ("Las Vírgenes milagrosas" y "Como se me ocurrió escribir esta leyenda"), de carácter introductorio, que son los que contienen consideraciones más subjetivas; de los restantes sólo apunta que "no es mas que pura historia del Santuario de Pastoriza, adornada con rasgos de erudición y entrelazada con hermosas flores poeticas".

En dos pasajes aprecia "algun tufillo, permitame V. E. la expresion, de naturalismo filosofico", porque la autora se olvida del papel de la fe y del orden sobrenatural en los afectos dispensados a la Madre de Dios, y sólo da protagonismo al corazón humano y a los sentidos, que nada pueden sin la fe y la Gracia Divina.

Es curiosa la tacha contra la equiparación que la autora establece entre las imágenes de la Virgen y "la columna fundida con el bronce de los cañones ganados en cien batallas", alusión a la columna Vendôme de París ubicada en la plaza homónima, revestida con las planchas del bronce obtenido de los cañones en la victoria francesa en Austerlitz. Ciertamente una comparación desafortunada, no queda más remedio que concordar con el clérigo: comparar un icono religioso con un monumento erigido al gran secularizador que fue Napoleón; en fin, una "comparacion algo profana y poco respetuosa á la Madre de Dios", pero inserta en su francofilia, que se inició ya en su primer periplo por Francia, en 1871, y se afianzó con la lectura de la literatura francesa (Balzac, Flaubert, los Goncourt, Daudet, Maupassant), su formación en el Colegio Francés y posteriores estancias en el país vecino.

Reproche de la misma naturaleza es el de equiparar el afecto por estas imágenes con el que se tiene "por los muebles viejos". Sorprendentemente, un canónigo tan quisquilloso no ve objeción, sin embargo, en la peculiar equiparación de la Virgen de los Ojos Grandes con $\operatorname{Argos}^{10}$, un personaje de la mitología griega, pagana por tanto: “¿Quién no conoce á la divina Argos, que ilumina con la claridad de sus grandes ojos negros la catedral lucense?" (Pardo Bazán 1887: 8). Bien es cierto que la expresión no se debe a la escritora, sino a una obra de Juan Pallares y Gaioso, de

10 Argo o Argos es un ser mitológico de uno, cuatro o infinidad de ojos distribuidos por todo el cuerpo, dependiendo de la versión mítica (Grimal 1990: 46). 
1700: Argos Divina Sancta María de Lugo de los Ojos grandes ${ }^{11}$. La expresión debió de ser muy sugestiva para la Pardo Bazán, ya que recurre a ella, no sin humor, en las novelas Doña Milagros (1894) y Memorias de un solterón (1896). En la primera, a propósito de Argos divina, mote de María Ramona, se dice que procede del "nombre que un librote del siglo pasado da a la Virgen del camarín de la Catedral [de Lugo], más conocida por Nuestra Señora de los ojos grandes" (Pardo Bazán 1919: 34). En la segunda leemos que don Benicio tiene dos hijas "que ofrecían verdaderas singularidades en su manera de ser: Argos divina y Feíta" (Pardo Bazán 2006: 227).

En otra ocasión reprocha el empleo del adjetivo "infinita" para aludir a la majestad del cielo, porque, conforme a la ontología escolástica, la infinitud es cualidad solo aplicable a Dios en cuanto Creator ex nihilo, mas no a lo creado, a sus criaturas, como lo es obviamente el firmamento, la "boveda soberana de lapiz lazuli" a la que alude doña Emilia. Únicamente Dios puede crear de la nada, y sólo de él puede decirse que es verdaderamente infinito y eterno. La infinitud de Dios supera cualquier otra infinitud pensable, incluida la del tiempo, el espacio y los números. Dios es, en suma, infinitamente infinito. Tomás de Aquino ${ }^{12}$ afirma que la infinitud no existe en las cosas sensibles y, en general, en lo creado; es más, el propio Dios, con toda su omnipotencia, no podría crear algo absolutamente infinito. La escritora incurre, por tanto, en una falta de "rigor teologico" que no pasa desapercibida al atento censor, cuyas objeciones obviamente no debían de ser insalvables, ya que el canónigo otorga el nihil obstat y el consecuente imprimatur:

\section{Exmo Señor:}

En cumplimiento de lo que V. E. I. se ha servido encomendarme, he examinado detenidamente el folleto escrito $p^{r}$. D $D^{a}$. Emilia Pardo Bazan intitulado "La Leyenda de la Pastoriza", y no he encontrado en él cosa alguna que se oponga al dogma católico y sana moral, $p^{r}$ lo cual, en mi humilde entender, puede

V. E. I. permitir su publicacion.

Dios gue á V. E. R. ms. as. Coruña Agosto 31 de 1887.

De V. E. R. humilde servidor y capellan Manuel $M^{a}$ Ojea

Excmo Señor Arzobispo de Santiago

(AHDS, F. General, Instrucción Pública, 1777-1898, Censura para la impresión de trabajos, "Libros prohibidos. Otros antecedentes", núm. 473).

\footnotetext{
11 El título completo es Argos Divina Sancta María de Lugo de los Ojos grandes, Fundación, y Grandezas de su Iglesia, Sanctos naturales, Reliquias, y Venerables Varones de su Ciudad, y Obispado, Obispos y Arçobispos que en todos Imperios la gouernaron/obra postvma, compuesta por ... Juan Pallares y Gaioso. Hay copia digital en http://www.galiciana.bibliotecadegalicia.xunta.es.

12 Phys., III, lect. 9 y VIII, lect. 2. De caelo, I, lect. 9. Met., XI, lect. 10 y XII, lect. 5. S. Theol. I. q. XLII, 2; XLVI, 1 y 2; y L. 2 ad 4.
} 
De hecho, en la última página de La Leyenda de Pastoriza consta, como era habitual, que "Se terminó la impresión de esta obra, con la censura y licencia eclesiástica, el día 30 de Agosto MDCCCLXXXVII".

No hay que descartar que doña Emilia conociese al comisionado don Manuel María Ojea y Castro, pues era Canónigo Magistral de la Real e Insigne Colegiata de A Coruña, del que hemos conseguido averiguar lo que aquí más nos interesa: sus "méritos, grados y ejercicios literarios", tal y como consta en un documento de dicha Colegiata, una especie de currículum vitae ${ }^{13}$. Natural de Santa María de Amoeiro, contaba con 52 años cuando escribe su dictamen. Estudió y aprobó en el Seminario Conciliar de la Diócesis de Lugo, con notas aventajadas, los cuatro cursos de Latinidad y Humanidades, tres de Filosofía y seis de Sagrada Teología, siete años en clase de interno y los restantes como externo, habiendo obtenido la beca para aquellos por oposición. También por oposición obtuvo, en dicho Seminario de Lugo, la clasicatura en Sagrada Teología. Fue catedrático de Canto Eclesiástico, grado de bachiller en Sagrada Teología, licenciado en Teología por Salamanca y aprobó en este Seminario Conciliar Derecho Canónico. Opositó a las Canongías Magistrales de la colegiata de A Coruña, y de las catedrales de Ourense, Santander y Tui. Formación intelectual no le faltaba al clérigo, ciertamente, y así lo revela en sus finas y argumentadas censuras.

\section{DOÑA EMILIA, ERUDITA ENMENDADA}

Mención aparte merece una peculiar "censura a posteriori", si se nos permite el término, de algún párroco seguramente, pues a tal palabra pensamos que se refiere la expresión "N. del P." ("Nota del Párroco"). La letra no parece la de don Víctor Cortiella. Sobre el ejemplar de la obra que se conserva en el Archivo Histórico Diocesano de Santiago, enmendó el corrector la plana a doña Emilia en algunos pasajes mediante notas manuscritas que corrigen algunos pormenores de esta "pura historia del Santuario de Pastoriza, adornada con rasgos de erudición". Es interesante reproducir los corrigenda a esta presunta erudición de doña Emilia:

En el pasaje que comienza con "Según Luitprando $\left({ }^{*}\right) . .$. ", en la página 22, se incorpora una "Nota: *Ese Luitprando no merece en sério crédito alguno, puesto que es una obra fabulosa que fingió el P. Roman de la Higuera, jesuita de Toledo. N. del P.".

En la página 27, en "sería su cuarta fase", el corrector tacha cuarta y añade "tercera".

13 AHDS, Fondo General, Serie Colegiatas, Colegiata de A Coruña (1743-1892), Mazo 3, núm. 339. 
En la página 28 se lee: “... la anexión de San Tirso de Oseiro á Pastoriza es bastante reciente" (1). Y la nota marginal dice: "(1) Esta anexión data del año de 1630; pero hubo otra de tiempo inmemorial anterior al año de 1571, y en ella apoya su aserto el $S^{r}$ Lopez Ferreiro. N. del P."

Por último, en la página 49 leemos que "Esta cabeza pasa por ser nada menos que la primitiva" $(*)$, a lo que el enmendador señala "(*) A pesar de ser esta cabeza un buen ejemplar de estilo bizantino, no puede pasar su antigüedad más allá del siglo XIII. N. del P."

\section{UN REPROCHE SINGULAR: EL "TUFILLO DE NATURALISMO FILOSÓFICO"}

Interesa, por último, analizar el contexto biográfico y literario de la autora en esta década de los ochenta. Sus experiencias vitales (separación conyugal, viajes) y literarias (crítica y teoría, novelas) arrojan luz sobre algunos aspectos relacionados con la Leyenda y el consiguiente informe. En primer lugar debemos destacar la encendida polémica a partir de la publicación de sus artículos en La cuestión palpitante en 1883, el mismo año de su separación conyugal, que causó no poco escándalo en la encorsetada y asfixiante sociedad provinciana de A Coruña. Se Ilegó a decir que un conocido sacerdote iba a arremeter contra la escritora desde el púlpito. En 1885 pasa el invierno en Francia, donde se reúne con Zola, pope de naturalismo, y otros escritores afamados; en 1886 publica Los Pazos de Ulloa; y en 1887 La Madre Naturaleza. De hecho se ha considerado este año como el "año glorioso" y cenit del prestigio de la escritora, que publica esta novela, considerada la culminación de la novela naturalista (Faus 2003: 373). Y el mismo año en que publica, por cierto, la "obrita o folleto" que nos ocupa.

La fe católica de la Pardo Bazán estaba fuera de toda duda. Su biógrafa BravoVillasante lo expresa nítidamente al abordar el "escándalo y polémica de La Cuestión Palpitante" (1973: 81 y ss.). El naturalismo de doña Emilia era un naturalismo católico o naturalismo a la española; el naturalismo pardobazaniano sigue la estética de la escuela francesa, pero no su fundamento filosófico, porque el determinismo de la herencia, el poder que ejerce la Naturaleza sobre los hombres, no se conjuga con su fe católica. Emile Zola mismo, dudaba de la adscripción de la escritora a dicha escuela. Y ella misma rechazaba las etiquetas naturalista, realista o idealista: se confesaba ecléctica. Era consciente de que un ingrediente fundamental del "escándalo" lo constituía el hecho de ser mujer.

Las relaciones con las más altas jerarquías eclesiásticas parecen avalar estos presupuestos. Sirva de mínimo pero significativo ejemplo la misiva enviada por el mismísimo Cardenal Arzobispo de Santiago, don Miguel Payá y Rico, para felicitarla 
por su obra San Francisco de Asís (1882) y animarla a seguir en su ortodoxia: "Tiempo ha que deseo espresar a V. mi satisfacción por observar en todas sus variadas producciones literarias de incontestable mérito la más pura y esquisita ortodoxia" (Freire López 1991: 92). Y años más tarde, cabe no olvidarlo, Benedicto XV le concederá la Cruz Pro Ecclesia et Pontifice.

Todo ello permite calibrar el interés que para el estudioso de la literatura presentan las dos alusiones del censor al "naturalismo filosofico", sin duda lo más relevante del informe, cuyo autor revela, con sutiles y afinadas consideraciones, sus profundos conocimientos de la filosofía escolástica -su currículum lo acredita-, como ha quedado de manifiesto en las objeciones ya analizadas y que ahora analizaremos.

Reprocha a la escritora el protagonismo por ella concedido a las pulsiones naturales en la devoción a la Virgen, que debería estar inspirada sobre todo por la fe. Cabe recordar que estas pulsiones naturales lo son también materiales, en la medida en que lo natural, lo nacido, lo creado por ende, es materia. Esta primacía de lo natural desplaza de su puesto soberano a "la fé y las demas gracias sobrenaturales", a través de los cuales conductos podemos acceder, conforme a la doctrina escolástica, a la verdad revelada, a los artículos de la fe (articula fidei) o misterios, en este caso la Virgen.

Cuestión diferente constituye la razón natural, que nos franquea el paso a las verdades naturales. La razón natural, por sí misma, únicamente puede conocer de abajo arriba, a partir de la experiencia sensorial; la fe, por el contrario, construye su conocimiento de arriba abajo, partiendo de la revelación divina. Sentimientos naturales y sentidos, es decir, "el corazon humano", deben auxiliar a la fe, y no viceversa, como parece sugerir doña Emilia y le afea el censor, a quien no huelen bien y emanan "cierto tufillo de naturalismo filosofico" unos párrafos "muy poco barnizados con el tinte del orden sobrenatural".

Es muy revelador, por coherente con las afirmaciones a las que objeta el censor, lo que la autora dice en La Cuestión Palpitante:

$Y$ es muy cierto que el naturalismo riguroso, en literatura y en filosofía, lo refiere todo a la naturaleza: para él no hay más causa de los actos humanos que la acción de las fuerzas naturales del organismo y el medio ambiente. Su fondo es determinista, como veremos.

Por determinismo entendían los escolásticos el sistema de los que aseguraban que Dios movía o inclinaba irresistiblemente la voluntad del hombre a aquella parte que convenía a sus designios. Hoy determinismo significa la misma dependencia de la voluntad, sólo que quien la inclina y subyuga no es Dios, sino la materia y sus fuerzas y energías. De un fatalismo providencialista, hemos pasado a otro materialista. (Pardo Bazán 1988: 145). 
La interpenetración, defendida por la escritora, entre lo natural y lo espiritual en el origen de la devoción a la Virgen también se compadece con lo que afirma en La Cuestión Palpitante:

Jamás negó la sabia teología católica semejantes obstáculos, ni desconoció la mutua influencia del cuerpo y del alma, ni consideró al hombre espíritu puro, ajeno y superior a su carne mortal; y los psicólogos y los artistas aprendieron de la teología aquella sutil y honda distinción entre el sentir y el consentir, que da asunto a tanto dramático conflicto inmortalizado por el arte. (Pardo Bazán 1988: 148).

Doña Emilia plantea la cuestión de la devoción mariana en términos absolutamente coherentes con lo que dejó escrito. Y el plácet del benévolo censor comisionado no deja de ser también coherente con lo que advirtió Emile Zola, el pontífice del naturalismo, que en cierto modo renegó de ella:

Lo que no puedo ocultar es mi extrañeza de que la Sra. Pardo Bazán sea católica ferviente, militante, y a la vez naturalista; y me lo explico sólo por lo que oigo decir de que el naturalismo de esa señora es puramente formal, artístico y literario (Pardo Bazán 1988: 122).

Para Alberto Savine era la Pardo Bazán "el jefe indiscutible de la escuela naturalista católica" (Pardo Bazán 1988: 120). Nada debía temer la Iglesia, pues "Emilia Pardo es católica, sinceramente religiosa", decía el temible y temido Clarín (Pardo Bazán 1988: 132).

¿Qué pensaría doña Emilia de este don Manuel María Ojea, si ella pudiera llegar a leer (que no a "oler") lo que nosotros hemos podido leer más de dos siglos después: ese "tufillo de naturalismo filosofico"? ¿Qué sonrisa irónica no esbozaría ante un censor a quien la mera presencia del adjetivo "natural" parece sugerirle, como un resorte -podría pensar ella-, la objeción "naturalismo filosofico"? No adjetivaba cualquiera: era doña Emilia Pardo Bazán, enfant terrible, siempre ella una cuestión palpitante. 


\section{FONDOS DOCUMENTALES}

Archivo Histórico Diocesano de Santiago. Fondo General, Serie Colegiatas, Colegiata de A Coruña (1743-1892), Mazo 3, núm. 339.

Archivo Histórico Diocesano de Santiago. Fondo General, Serie Instrucción Pública (1777-1898), Censura para la impresión de trabajos, "Libros prohibidos. Otros antecedentes", núm. 473.

Archivo Histórico Diocesano de Santiago. Fondo Parroquial de Nuestra Señora de Pastoriza (1887), sección $1^{\mathrm{a}}$, legajo A, núm. 15.

Archivo Histórico Diocesano de Santiago. Fondo Parroquial de San Jorge de A Coruña, Libro de Bautizados, núm. 34 (1889-1895), 35 (1895-1901), 36 (1901-1907) y 37 (1907-1913).

Archivo Histórico Diocesano de Santiago. Fondo Parroquial de San Jorge de A Coruña, Libro de Difuntos, núm. 68 (1910-1917).

\section{BIBLIOGRAFÍA}

Barreiro Fernández, Xosé Ramón, et alii (2008): "Aportaciones a la biografía de Emilia Pardo Bazán. La crisis matrimonial (1875-1884)", in La Tribuna. Cadernos de Estudos da Casa Museo Emilia Pardo Bazán, núm. 6, A Coruña, pp. 71-128.

Bravo-Villasante, Carmen (1973): Vida y obra de Emilia Pardo Bazán. Correspondencia amorosa con Pérez Galdós, Madrid, Editorial Magisterio Español.

Carré Aldao, Eugenio (ca. 1928): La Coruña, vol. V, tomo 1º, in Geografía General del Reino de Galicia, dirigida por F. Carreras y Candi, La Coruña, Ediciones Gallegas.

Cebrián Franco, Juan José (1982): Santuarios de Galicia (Diócesis de Santiago de Compostela), Santiago de Compostela, Arzobispado de Santiago de Compostela.

Faus Sevilla, Pilar (2003): Emilia Pardo Bazán. Su época, su vida, su obra, A Coruña, Fundación Pedro Barrié de la Maza.

Fernández Fuster, Luis (1974): Teoría y técnica del turismo, tomo I, Madrid, Editora Nacional.

Ferreiro, Manuel (1991): Pondal: do dandysmo á loucura (biografia e correspondéncia), Vigo, Laiovento.

Freire López, Ana María (1991): Cartas inéditas a Emilia Pardo Bazán (18781883), La Coruña, Fundación Pedro Barrié de la Maza.

García Morales, María Victoria; Soto Caba, Victoria (2011): Patrimonio Histórico Artístico, Madrid, Editorial Universitaria.

Grimal, Pierre (1990): Diccionario de mitología griega y romana, Barcelona, 
Grupo de investigación La Tribuna (2009): "La riqueza de Emilia Pardo Bazán. Una aproximación a su estudio", in La Tribuna. Cadernos de Estudos da Casa Museo Emilia Pardo Bazán, núm. 7, A Coruña, pp. 37-79.

Pardo Bazán, Emilia (1887): La Leyenda de la Pastoriza, La Coruña, José Miguez Peinó y Hermano Impresores. Copia digital en http://www.galiciana. bibliotecadegalicia.xunta.es.

Pardo Bazán, Emilia (1919): Doña Milagros, Madrid, Librería de Pueyo.

Pardo Bazán, Emilia (1984): Cuentos, edición de Juan Paredes Núñez, Madrid, Taurus.

Pardo Bazán, Emilia (1984): De mi tierra, Vigo, Edicións Xerais de Galicia.

Pardo Bazán, Emilia (1988): La Cuestión Palpitante; edición, estudio introductorio, notas y apéndice de José Manuel González Herrán, Universidad de Santiago de Compostela.

Pardo Bazán, Emilia (1995): La Tribuna, edición de Benito Varela Jácome, Madrid, Cátedra Letras Hispánicas.

Pardo Bazán, Emilia (2006): La educación del hombre y la de la mujer. La dama joven. Memorias de un solterón, edición de Marina Mayoral, Santiago, Sotelo Blanco.

Paredes Núñez, Juan (1983): La realidad gallega en los cuentos de Emilia Pardo Bazán (1851-1921), Sada, Ediciós do Castro, Serie Liminar Filoloxía.

Pérez Sánchez, Yolanda (2006): “La escritora en el balneario. Emilia Pardo Bazán y Mondariz", in La Tribuna. Cadernos de Estudos da Casa Museo Emilia Pardo Bazán, núm. 4, A Coruña, pp. 271-290.

Thion Soriano-Mollá, Dolores (2005): “El epistolario de Doña Emilia Pardo Bazán, estado de la cuestión", in Emilia Pardo Bazán: Estado de la cuestión, A Coruña, Fundación Caixa Galicia, Casa-Museo Emilia Pardo Bazán, pp. 181-217.

Tomás de Aquino (1951): Obra completa, edición bilingüe, Madrid, Editorial Católica, Biblioteca de Autores Cristianos. 


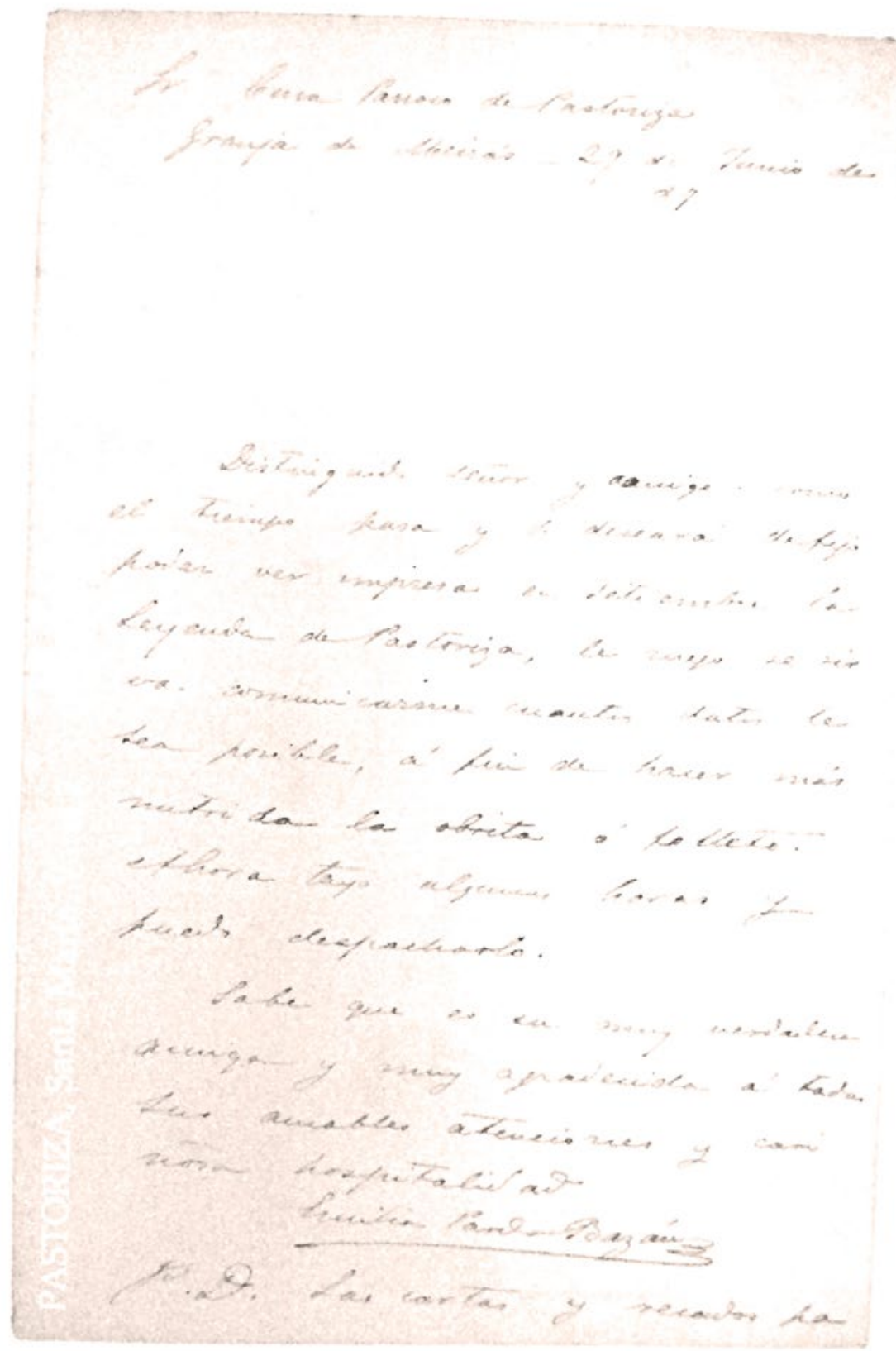




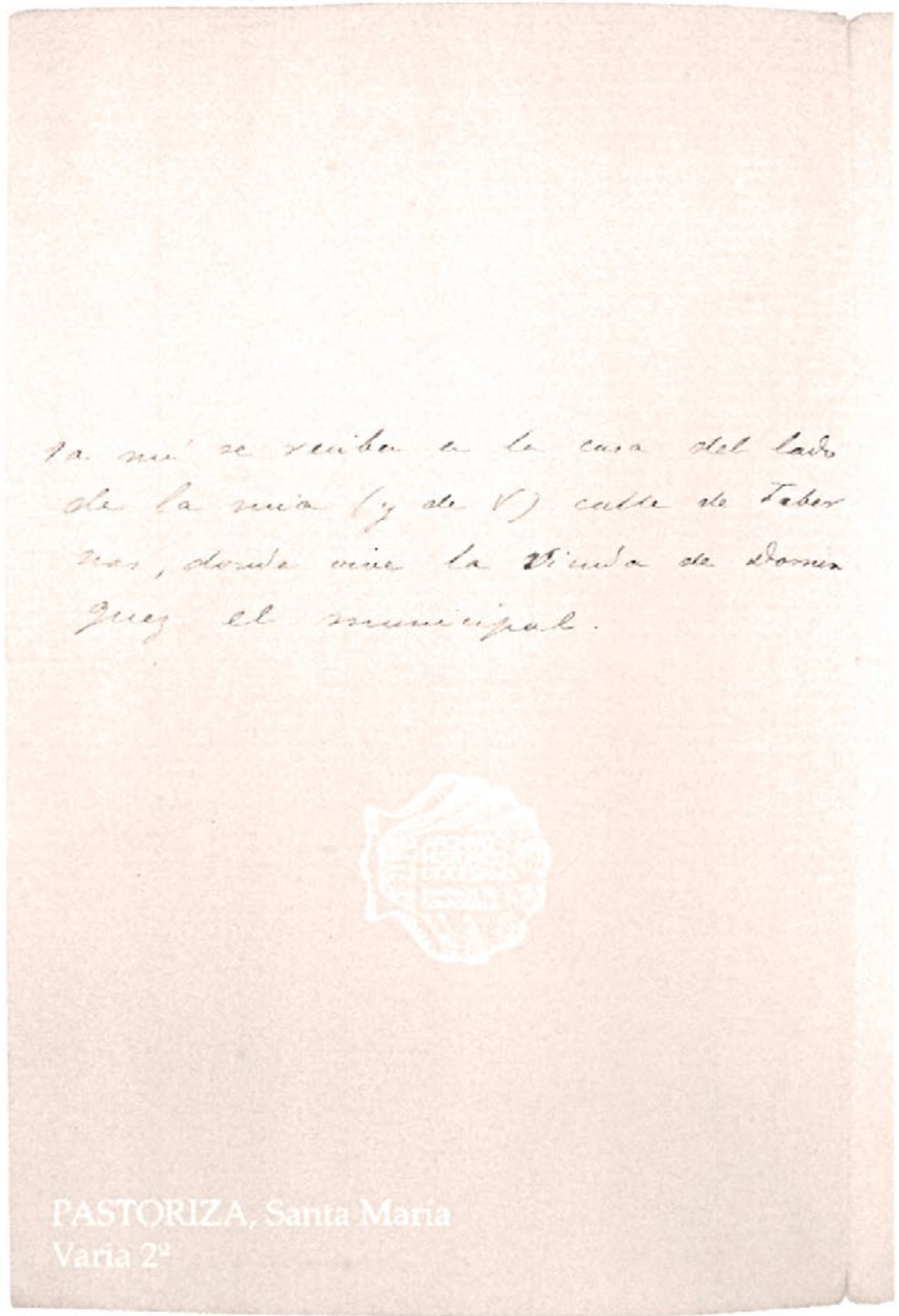




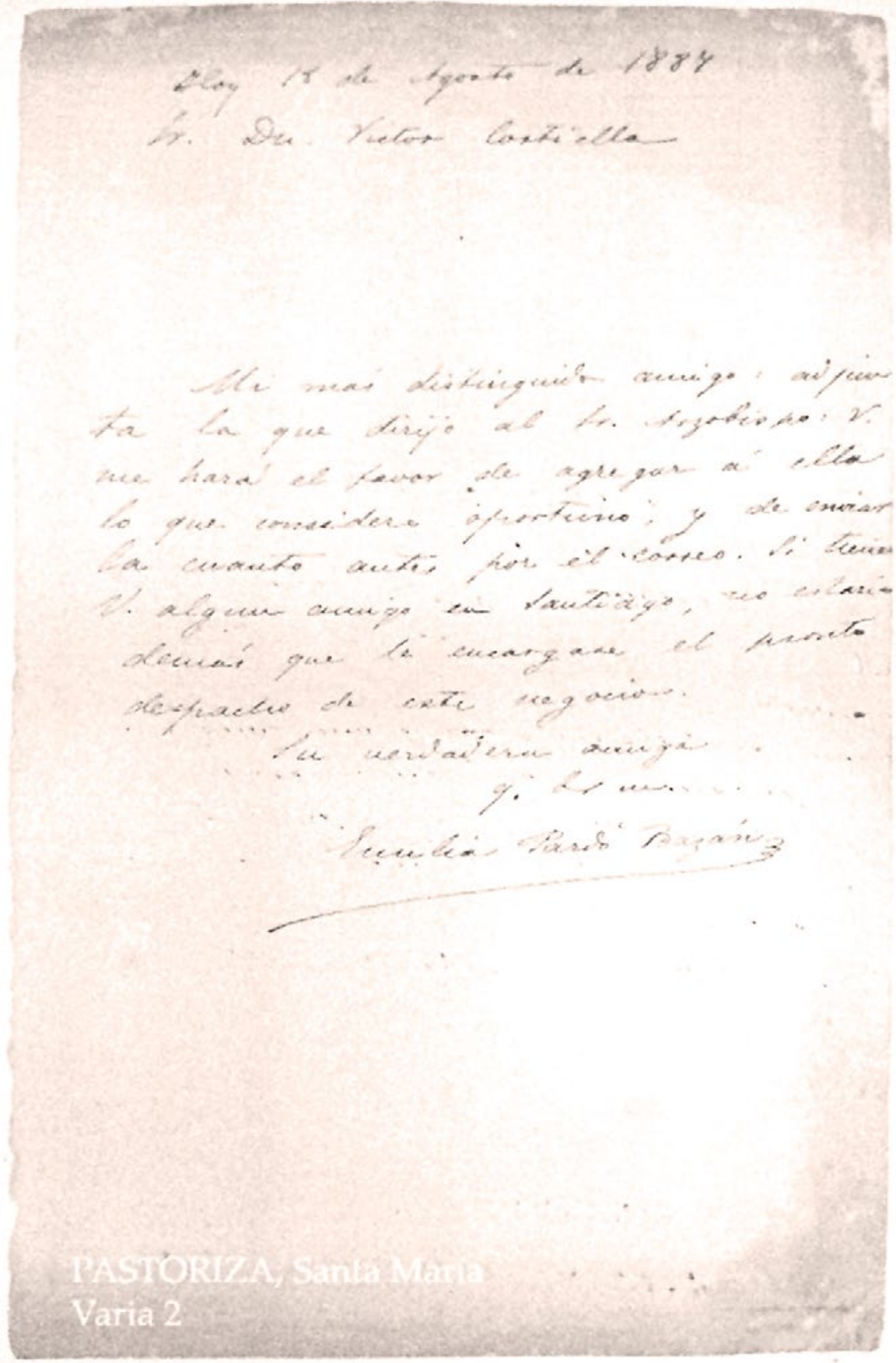


